\title{
Short-Period Internal Waves under an Ice Cover in Van Mijen Fjord, Svalbard
}

\author{
E. G. Morozov, ${ }^{1}$ S. V. Muzylev, ${ }^{1}$ A. S. Shestov, ${ }^{2,3}$ and A. V. Marchenko ${ }^{2,3,4,5}$ \\ ${ }^{1}$ P.P. Shirshov Institute of Oceanology, Russian Academy of Sciences, Moscow 117997, Russia \\ ${ }^{2}$ Department of Aerophysics and Space Research, Moscow Institute of Physics and Technology, 141700 Dolgoprudny, Russia \\ ${ }^{3}$ Department of Arctic Technology, The University Centre in Svalbard, 9171 Longyearbyen, Norway \\ ${ }^{4}$ N.N. Zubov State Oceanographic Institute, Moscow 119034, Russia \\ ${ }^{5}$ Sustainable Arctic Marine and Coastal Technology (SAMCoT), Centre 7491 for Research-Based Innovation (CRI), \\ Trondheim, Norway
}

Correspondence should be addressed to E. G. Morozov, egmorozov@mail.ru

Received 15 September 2011; Accepted 17 December 2011

Academic Editor: Irina Repina

Copyright (C) 2011 E. G. Morozov et al. This is an open access article distributed under the Creative Commons Attribution License, which permits unrestricted use, distribution, and reproduction in any medium, provided the original work is properly cited.

\begin{abstract}
Temperature and velocity fluctuations measured in Van Mijen Fjord in Svalbard and interpreted as the fluctuations induced by internal waves revealed the existence of short-period internal waves with an amplitude of approximately $1 \mathrm{~m}$ and a period of approximately 5-10 min that correlate with the ice cover fluctuations of the same period with an amplitude of a few millimeters.
\end{abstract}

\section{Introduction}

We analyze the measurements of temperature, velocity, and pressure at the bottom to study the influence of internal waves on the ice cover. The "rigid lid" approximation is almost always used in the theoretical study of internal waves under the ice cover or even without it. This approximation filters off the surface mode and adequately describes the properties of both the internal waves in ice-free conditions and long internal waves under the ice cover $[1,2]$. In the "rigid lid" approximation, the vertical velocity at the surface is assumed to be equal to zero; therefore, due to the kinematic condition, the internal waves cannot cause any vertical displacements of the ice cover. Such conclusion is, however, inconsistent with the experimental data obtained for relatively deep parts of the Arctic Ocean [3-6] and also contradicts the theoretical results $[7,8]$, according to which internal waves may be reflected in the fluctuations of the ice cover at frequencies comparable with the BruntVäisälä frequency. Scientists from the Shirshov Institute of Oceanology (Russian Academy of Sciences) and The University Centre in Svalbard (UNIS) carried out marine studies in the shallow Van Mijen Fjord in Svalbard to perform experimental tests of the theoretical conclusion concerning the possible influence of short internal waves on the fluctuations of the compact ice cover.

\section{Brief Theory of Internal Waves under an Ice Cover}

In the theoretical approach, the ice cover of the ocean surface can be considered as a thin elastic plate floating on the sea surface. The theoretical description of the ice cover fluctuations should take into account the elastic properties of the ice plate, the compression forces, and the ice inertia. If the processes inside the ice cover are ignored the main equations and boundary conditions of the ice cover should be similar to the equations and conditions in the situation when the sea surface is free of ice.

The only exception is the dynamic condition that may be expressed under the constant ice thickness $h$ in the following form $[7-11]$ :

$$
\left.P\right|_{z=0}=\rho_{0} g \eta+\left[\rho_{0}\left(B \Delta^{2}+Q \Delta\right) \eta\right]+\rho_{0} M \frac{\partial^{2} \eta}{\partial t^{2}} .
$$

Here, $P$ is the pressure, $\eta$ the ice surface deflection, $g$ the acceleration due to gravity, $\rho_{0}$ the seawater density at the 
boundary with the ice, $t$ the time, $\Delta$ the horizontal Laplace operator, and

$$
B=\frac{E h^{3}}{12\left(1-s^{2}\right) \rho_{0}}, \quad Q=\frac{K h}{\rho_{0}}, \quad M=\frac{\rho_{I} h}{\rho_{0}} .
$$

Here, $B$ is the cylindrical rigidity of the ice, the $E$ Young's modulus, $s$ the Poisson's ratio, $K$ the ice compression coefficient, $\rho_{I}=$ const the ice density, and $h=$ const the ice thickness.

In (1), the summands proportional to $B, M$, and $Q$ result from the respective elastic ice properties, the inertial forces, and the compression forces, which influence the ice cover. The characteristic values (2) for the ice are as follows $[12,13]$ : $E=3 \cdot 10^{9} \mathrm{~N} / \mathrm{m}^{2}, s=0.3, K=2 \cdot 10^{5} \mathrm{~N} / \mathrm{m}^{2}, \rho_{0}=1025 \mathrm{~kg} / \mathrm{m}^{3}$, and $\rho_{I}=0.9 \rho_{0}$. With the ice thickness $h=0.5 \mathrm{~m}$ observed during the experiment, we obtain the following estimates for the coefficients: $B \approx 3.35 \cdot 10^{4} \mathrm{~m}^{5} / \mathrm{s}^{2}, Q \approx 97.6 \mathrm{~m}^{3} / \mathrm{s}^{2}$, and $M=0.45 \mathrm{~m}$. In the case of the ice-free surface, when $h=0$ and, consequently, $B=Q=M=0$, dynamic condition (1) acquires the standard form $\left.P\right|_{z=0}=\rho_{0} g \eta$.

We designate the characteristic horizontal scale of the wave motions as $L$. Comparing the summand in (1), which describes the contribution of the pressure determined by the elastic properties of the ice cover (summand proportional to the cylindrical ice rigidity $B$ ) into $\left.P\right|_{z=0}$, with the value of the gravity potential at the surface of the liquid $U_{s}=\rho_{0} g \eta$, we find that these summands are of the same order if $L \sim L_{\mathrm{eg}}$, where

$$
L_{\mathrm{eg}}=\left(\frac{B}{g}\right)^{1 / 4}=\left[\frac{E h^{3}}{12\left(1-s^{2}\right) \rho_{0} g}\right]^{1 / 4} .
$$

We assume that the properties of the waves under the elastic plate characterized by the lengths $L \gg L_{\text {eg }}$, are close to these parameters of the waves in the liquid with a free surface, and the ice cover insignificantly influences the wave motions in the sea. At the same time, for short waves with lengths $L \ll L_{\text {eg }}$ the elasticity forces of the plate prevail over the gravity forces.

Let us compare the gravity potential $U_{s}$ with the pressure determined by the compression forces in the ice cover (with the summands proportional to $Q$ ). We obtain that they are of the same order if $L \sim L_{\text {eg }}$, where

$$
L_{\mathrm{eg}}=\left(\frac{Q}{g}\right)^{1 / 2}=\left(\frac{K h}{\rho_{0} g}\right)^{1 / 2} .
$$

If the ice thickness is $h_{*}=12\left(1-s^{2}\right) K^{2} / \rho_{0} g E$, we get that $L_{\mathrm{eg}} \approx L_{\mathrm{cg}}$; therefore, for the ice cover with a thickness exceeding $h_{*}$, the inequality $L_{\mathrm{eg}}>L_{\mathrm{cg}}$ is valid. The contribution of the elastic forces to $\left.P\right|_{z=0}$ is comparable with that of the compression forces if characteristic motion scale is $L \sim L_{\mathrm{ec}}$, where

$$
L_{\mathrm{ec}}=\frac{L_{\mathrm{eg}}^{2}}{L_{\mathrm{cg}}}=\sqrt{\frac{B}{Q}}=h \sqrt{\frac{E}{12\left(1-s^{2}\right) K}} .
$$

Since inequality $L_{\mathrm{eg}}>L_{\mathrm{cg}}$ is valid for the ice thickness greater than $h_{*}$, then $L_{\mathrm{ec}}>L_{\mathrm{eg}}>L_{\mathrm{cg}}$. Although, at $L>L_{\mathrm{ec}}$, the ice compression forces exceed the elasticity forces, the gravity force appears to be decisive for the wave motion. At $L<L_{\mathrm{ec}}$, the determining role belongs either to the gravity force when $L \in\left(L_{\mathrm{ec}}, L_{\mathrm{eg}}\right)$ or to the elasticity if $L<L_{\mathrm{eg}}$.

Usually we can neglect the role of the inertia forces in the case of compact ice cover. However, we note that due to (1) an increase in the wavelength is accompanied by an unlimited growth of the pressure at the lower ice boundary. In order to exclude its unlimited growth, the ice deflection should tend to zero with the simultaneous wavelength reduction. We also note that all the estimates were obtained under the assumption that the motions in the horizontal plane are uniform. Near the lateral boundaries and in the case of sharp bottom topography gradients, these estimates should be revised.

The previous qualitative results are valid for the waves of any type under compact ice cover, while the quantitative data are now obtained for the flexure-gravity waves [7], edge waves near the straight coast above the sloping bottom [11], waves spreading along the ice field edge $[14,15]$, and internal waves $[7,8]$. We emphasize three issues, which are important for the description of internal waves when the water stratification in the basin allows the Brunt-Väisälä frequency $N$ to be considered constant.

(1) The dispersion equation for such waves takes the following form:

$$
\lambda_{n} \tan \lambda_{n} H=\frac{N^{2}-\omega_{n}^{2}}{g+B k^{4}-Q k^{2}-M \omega_{n}^{2}},
$$

where $\lambda_{n}=k \sqrt{\left(N^{2}-\omega_{n}^{2}\right)} / \omega_{n}, \omega_{n}$ is the frequency of internal waves, $k$ the magnitude of the wave number, $H=$ const the basin depth, and $n$ the mode number.

(2) The ice thickness $h$ provides an insignificant impact on the dispersion equation $(6)[7,8]$; therefore, it can be presented with high accuracy in its classical form:

$$
\omega_{n}(k) \approx \frac{k H}{\sqrt{n^{2} \pi^{2}+k^{2} H^{2}}} N .
$$

(3) One can show for internal waves propagating in the lateral direction that the amplitude of the ice deflection $\eta_{n}$ for the mode with the $n$ number and the pressure amplitude $p_{n}(z)$ at depth $z$ are connected by the following relation $[7,8]$ :

$$
\begin{aligned}
\eta_{n}= & \frac{p_{n}(z)}{\rho_{0}\left[g+B k_{n}^{4}(\omega)-Q k_{n}^{2}(\omega)-M \omega^{2}\right]} \\
& \times \frac{\cos \lambda H}{\cos \lambda(H+z)} .
\end{aligned}
$$

If $z=-H$, the following relationship exists between the ice deflection and the pressure at the bottom: $p_{b, n}=p_{n}(-H)$ :

$$
\eta_{n}=\left(\frac{p_{b, n}}{g \rho_{0}}\right) \frac{g \cos \lambda H}{g+B k_{n}^{4}(\omega)-Q k_{n}^{2}(\omega)-M \omega^{2}} .
$$




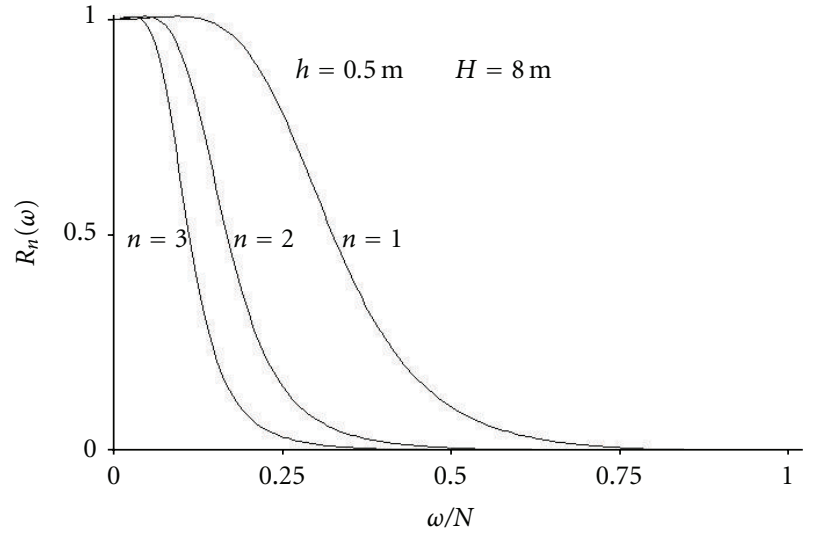

(a)

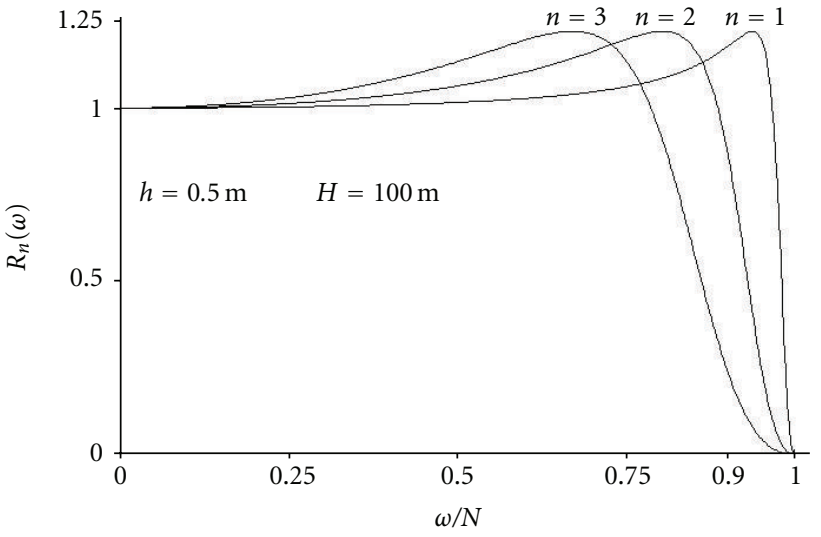

(b)

FIGURE 1: Transfer function determining the correction factor for the hydrostatic relation between the amplitudes of the near-bottom pressure and the ice deflection with the thickness of the ice cover $h=0.5 \mathrm{~m}$ and the sea depth (a) $H=8 \mathrm{~m}\left(K=2 \times 10^{5} \mathrm{~N} / \mathrm{m}^{2}\right)$ and (b) $H=100 \mathrm{~m}\left(K=10^{6} \mathrm{~N} / \mathrm{m}^{2}\right)$.

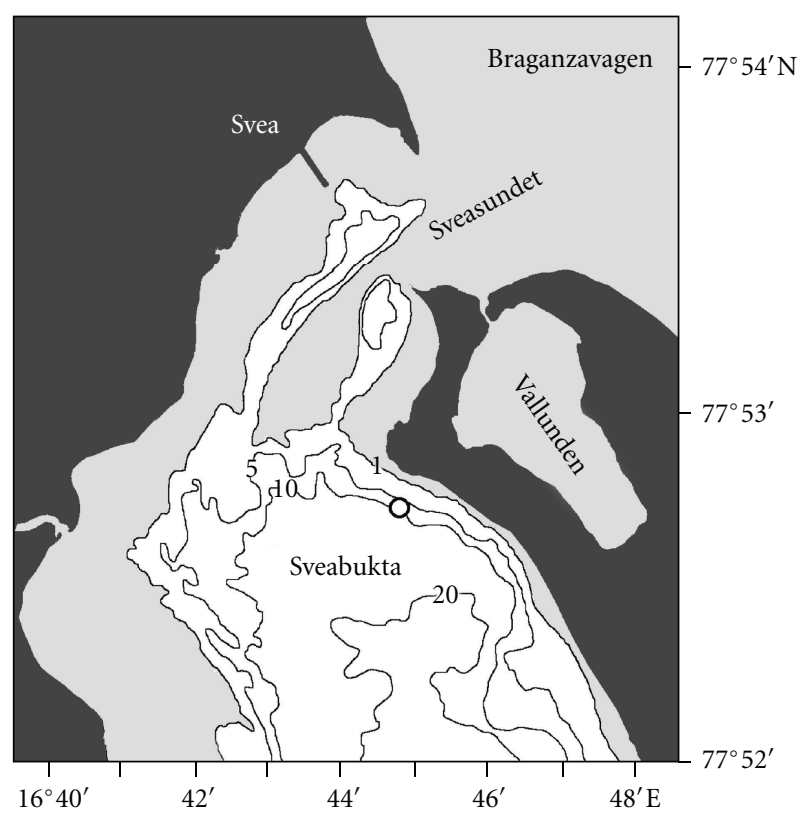

FIGURE 2: Schematic map of the measurement site. Gray color shows shallow $(<1 \mathrm{~m})$ regions. Black color denotes land. The circle indicates the site of measurements.

Relation

$$
R_{n}(\omega)=\left|\frac{g \cos \lambda H}{g+B k_{n}^{4}(\omega)-Q k_{n}^{2}(\omega)-M \omega^{2}}\right|
$$

can be interpreted as a transfer function that determines the correction factor for the hydrostatic relationship between the pressure at the bottom and ice deflection.

The dependences of the transfer function $R_{n}(\omega)$ for both the conditions of the performed natural experiment and the above-mentioned values obtained for the coefficients $B, Q$, and $M$ (Figure 1(a)) and the conditions described in [10]

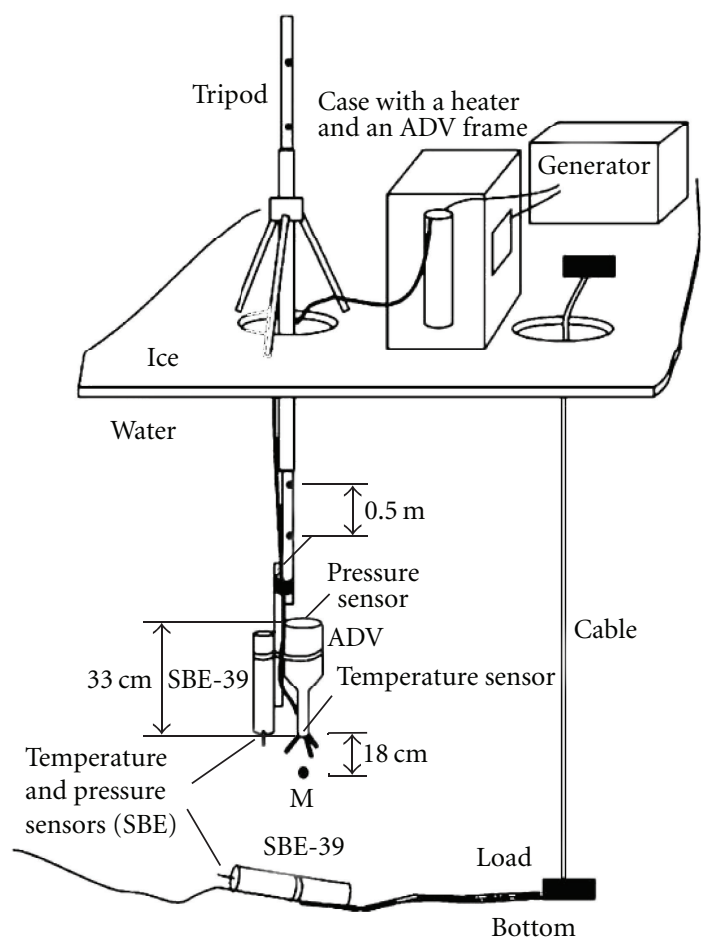

FIgURE 3: Schematic location of the measuring devices (M corresponds to the current measurement point).

(Figure 1(b)) are shown in Figure 1. The form of the transfer function $R_{n}(\omega)$ significantly depends on the depth of the basin (the deeper the basin, the closer the maximum of the transfer function to the Brunt-Väisälä frequency) and the compression coefficient $Q$ (the greater the latter, the larger the maximum of the transfer function). We note that, immediately near the Brunt-Väisälä frequency, when the internal waves are very short, the transfer function tends to zero due to (10); that is, in this frequency range, the ice cover should flatten. 


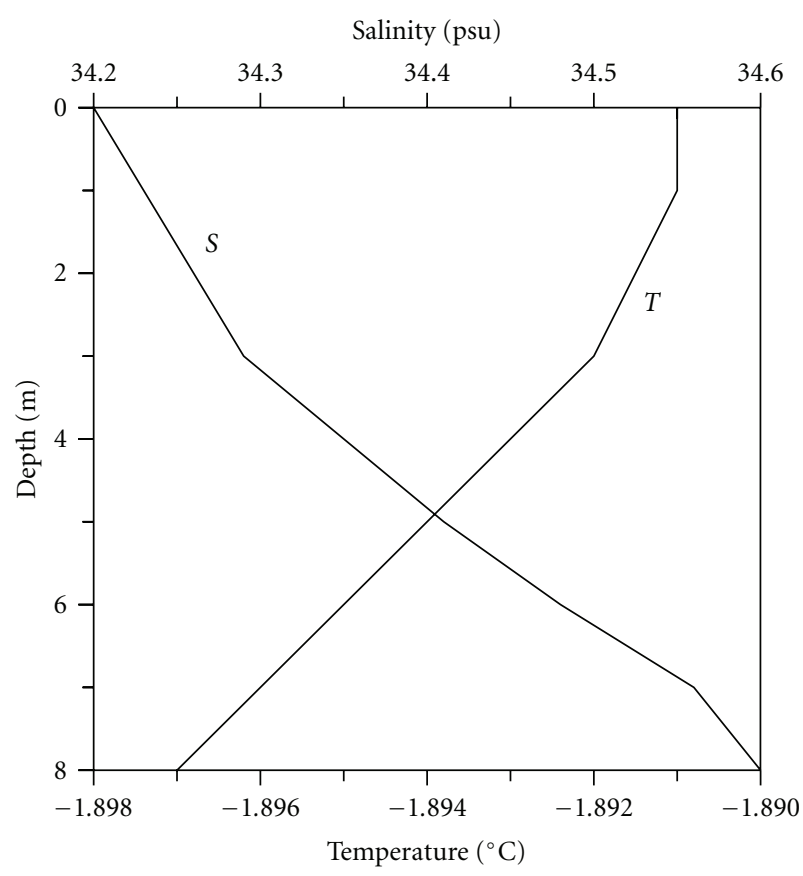

(a)

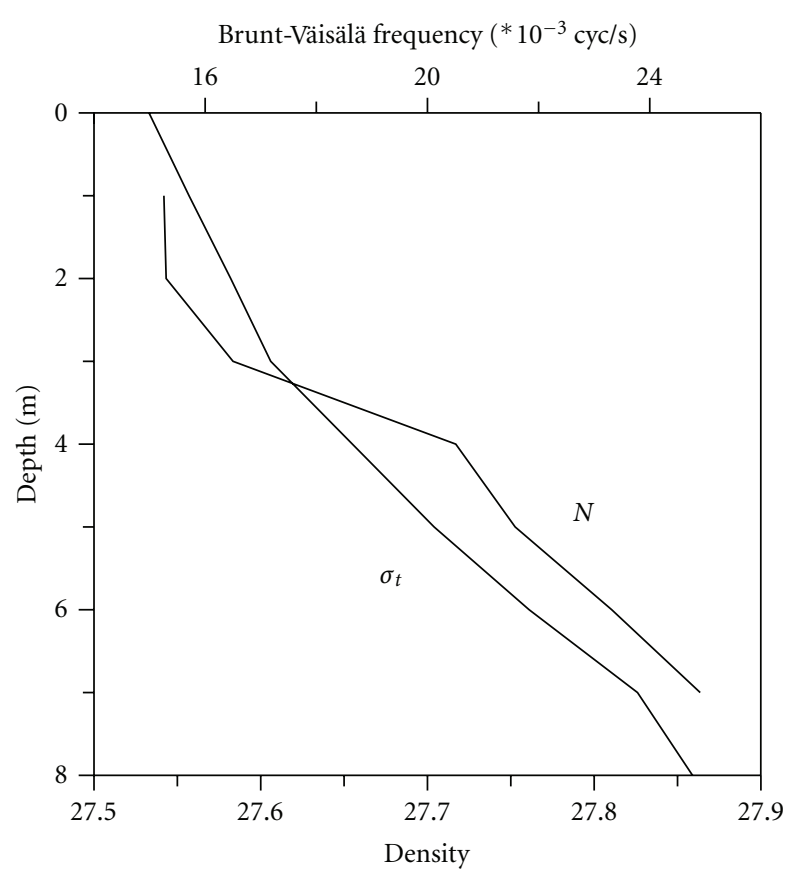

(b)

Figure 4: Vertical distribution of temperature $(T)$, salinity $(S)$, density $\left(\sigma_{t}\right)$, and Brunt-Väisälä frequency $(N)$ in the study region.

\section{Measurements of Internal Waves in the Van Mijen Fjord under the Ice Cover}

In 2008, simultaneous measurements of internal waves and pressure at the sea bottom that reflect the fluctuations of the ice cover were carried out in the Van Mijen Fjord. Figure 2 demonstrates the location of the study region.

Temperature profiler SBE 39 with a high-accuracy pressure sensor and a current meter (SonTek ADV Ocean Probe) were used during the field works. The SBE 39 profiler measures the temperature with a resolution of $0.0001^{\circ} \mathrm{C}$ and the pressure with a resolution of $0.002 \%$ of the pressure scale of $20 \mathrm{dbar}$, which corresponds to a pressure resolution of 0.004 dbar (or, approximately, to $0.4 \mathrm{~mm}$ of depth). The ADV measuring instrument provides data of three velocity components with a resolution of $0.01 \mathrm{~cm} / \mathrm{s}$. Measurements were conducted under the ice using the instruments mounted on a vertical support rod with a tripod standing on the ice (Figure 3).

The pressure meter SBE 39 was located at the bottom to measure the fluctuations of the ice cover. The measurements were conducted under the ice $50-60 \mathrm{~cm}$ thick in the region with strong tidal currents: the heights of the spring tide reached $2 \mathrm{~m}$, and the maximal tide velocity was as high as $10 \mathrm{~cm} / \mathrm{s}$. During the observation period, the water temperature was close to the freezing point (approximately $\left.-1.9^{\circ} \mathrm{C}\right)$. Insignificant vertical temperature gradient $(1 \times$ $\left.10^{-3 \circ} \mathrm{C} / \mathrm{m}\right)$ and high salinity $(0.05 \mathrm{psu} / \mathrm{m})$ gradients were characteristic of the measurement period. Figure 4 illustrates the vertical distribution of the temperature, salinity, density, and Brunt-Väisälä frequency. The profile of the density practically repeats that of the salinity, which indicates that the downward density changes are determined by the variations in the salinity. The Brunt-Väisälä frequency in the study region was approximately $15-25 \times 10^{-3} \mathrm{cyc} / \mathrm{s}$ with twofold downward variations.

The most representative results of the measurements of short-period internal waves were obtained at the site with coordinates $77^{\circ} 52.79^{\prime} \mathrm{N}$ and $16^{\circ} 43.73^{\prime} \mathrm{E}$ and a depth of approximately $10 \mathrm{~m}$ on the underwater slope of the sill between the deep and shallow parts of the bay. The calculations of the spectrum of temperature fluctuations show that, at frequencies exceeding the Brunt-Väisälä frequency, the spectrum sharply decreases with the increasing frequency, while, at the frequencies slightly lower than the buoyancy frequency, several peaks are observed. Let us analyze fluctuations with such periods.

The spectrum of the temperature fluctuations in the range of the short-period oscillations (Figure 5(a)) is characterized by two peaks with frequencies of 0.0015 and 0.003 cyc/s, which correspond to the periods of approximately 10 and $5.5 \mathrm{~min}$; the spectrum of the velocity fluctuations is characterized by similar patterns, although a significant peak is observed only at a frequency of $0.003 \mathrm{cyc} / \mathrm{s}$ or $5.5 \mathrm{~min}$ (Figure 5(b)).

The spectra of pressure fluctuations were also calculated from the data of bottom-located meter SBE 39. As it follows from (9), these pressure variations are responsible for fluctuations of the ice cover. Figure 5(c) demonstrates the spectrum of the pressure fluctuations, which is characterized by a peak at the period of approximately $5.5 \mathrm{~min}$ (frequency $0.003 \mathrm{cyc} / \mathrm{s}$ ). Such fluctuations were also reported in [16]. The amplitude of the pressure fluctuations at the bottom with such a period is $0.005-0.006 \mathrm{dbar}$, which corresponds, 


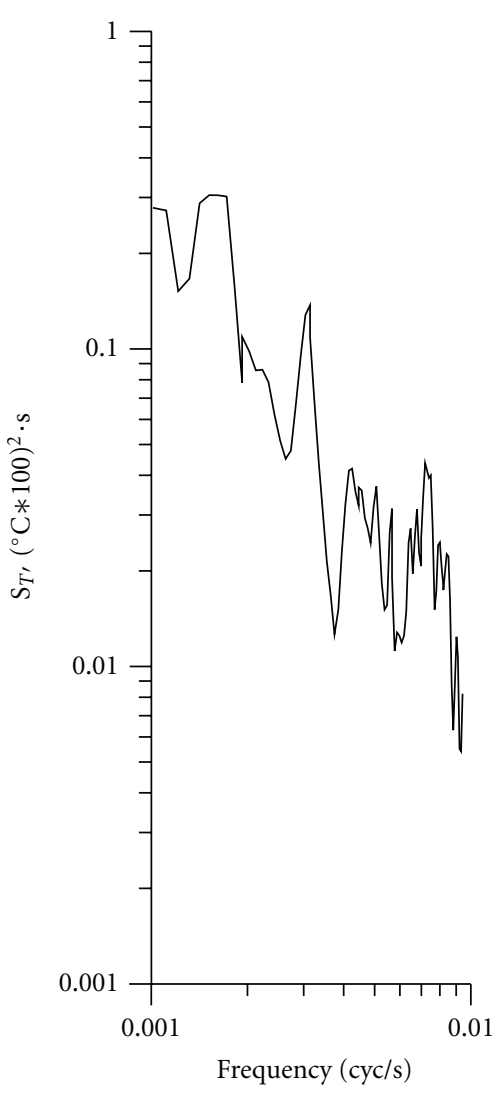

(a)

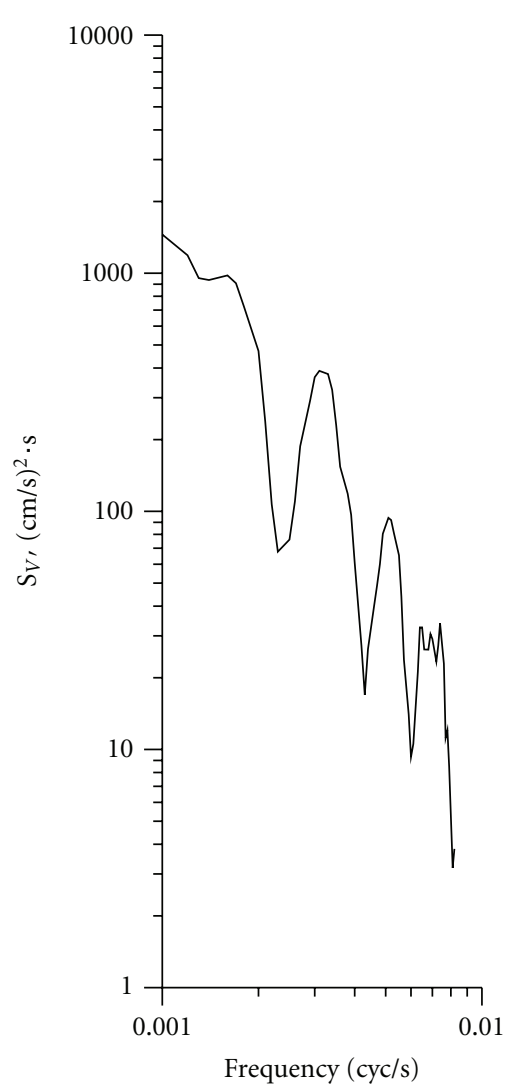

(b)

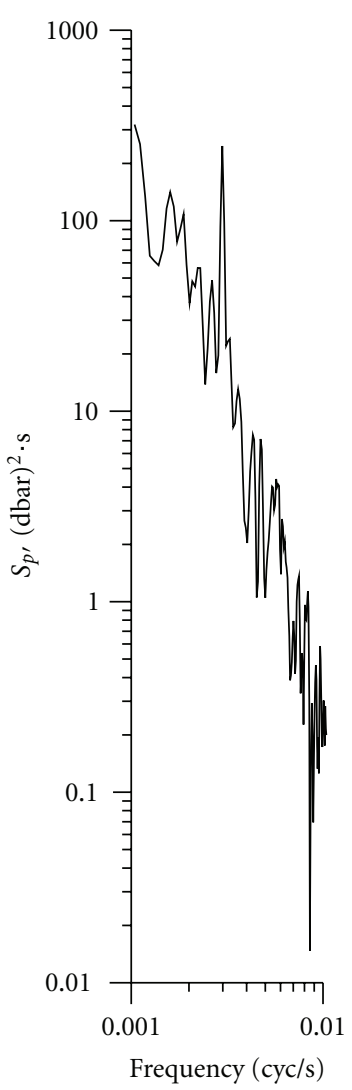

(c)

FIGURE 5: (a) spectrum of the temperature fluctuations in the high-frequency range; (b) spectrum of the current velocity fluctuations in the high-frequency range; (c) spectrum of the pressure fluctuations at the bottom in the high-frequency range.

according to (10), approximately to the amplitude of 5-6 $\mathrm{mm}$ of the fluctuations of the ice cover.

\section{Discussion and Conclusions}

Short intense internal waves can probably break the ice cover. Indeed, according to relation (1) for the pressure at the lower surface of the ice if $L \ll L_{\mathrm{eg}}$, or $L \ll L_{\mathrm{ec}}$ the value of relation $\rho_{0}\left(B \Delta^{2}+Q \Delta\right) \eta$ increases as the internal wavelength decreases. In other words, the contribution to pressure of the elastic and compression-tension forces applied to the ice cover increases. The following formula for maximal stress $\sigma_{\max }$ at the surface of bended elastic plate can be used to estimate ice break up by internal waves: $\sigma_{\max } \approx a E h k^{2} / 2$ [13 Landau Lifshits]. In our case, $a=5 \mathrm{~mm}, E=3 \mathrm{GPa}, h=0.5 \mathrm{~m}$ and $k=0.32 \mathrm{cyc} / \mathrm{m}$ (wave length is about $20 \mathrm{~m}$ ) according to the dispersion equation (7), where $H=10 \mathrm{~m}$ and $N=0.028 \mathrm{cyc} / \mathrm{s}$. The ice stress $\sigma_{\max }$ is estimated as $0.38 \mathrm{MPa}$. This value is close to the flexural strength of sea ice [17]. Thus, short internal waves can break up the ice cover.

It is possible that such phenomenon was observed during the expedition of R/V "Polarstern" in 1986 in the Weddell Sea [18, page 75] when the solid ice cover with a thickness of $0.8 \mathrm{~m}$ was suddenly broken [10]. A similar event occurred in the spring of 1988 near Sakhalin Island [19]. According to the data of observations, internal waves were evidently generated by an intense cyclone.

Thus, the study of short internal waves is important since they can influence the ice surface. The influence of atmospheric and oceanic processes and especially internal waves on the stability of the ice cover and ice cover depletion currently observed in the Arctic region in the summer season is the hot issue of polar meteorology and oceanography $[2,20]$. The winter measurements of temperature, velocity, and pressure fluctuations under ice in the frequency range of internal waves in the shallow Arctic Fjord in Spitsbergen demonstrate that the temperature and velocity fluctuations with periods of 5-10 min and the amplitude of the internal waves slightly less than $1 \mathrm{~m}$ correlate with the fluctuations of the ice cover of the same period and an amplitude of a few millimeters. These results are consistent with the theory.

\section{Acknowledgments}

The authors thank Professor F. Nilsen (UNIS) and K. Johansen for their help in conducting the field studies. This work was supported by the Russian Foundation for Basic Research (project nos. 08-05-00120, 08-05-00124, 09-0500599, 10-08-01010, 11-05-00448, 11-08-00076, and 12-0500889). The authors also thank anonymous reviewers for their valuable remarks. 


\section{References}

[1] E. G. Morozov, V. G. Neiman, S. V. Pisarev, and S. Yu. Erofeeva, "Internal tidal waves in the Barents Sea," Doklady Earth Sciences, vol. 393, no. 8, pp. 1124-1127, 2003.

[2] E. G. Morozov and S. V. Pisarev, "Internal waves and polynya formation in the Laptev sea," Doklady Earth Sciences, vol. 398, no. 7, pp. 983-986, 2004.

[3] P. V. Czipott, M. D. Levine, C. A. Paulson, D. Menemenlis, D. M. Farmer, and R. G. Williams, "Ice flexure forced by internal wave packets in the Arctic ocean," Science, vol. 254, no. 5033, pp. 832-835, 1991.

[4] V. N. Smirnov, "Oscillations of the ice cover induced by internal waves in an icy ocean," Doklady Akademii Nauk SSSR, vol. 206, no. 5, pp. 1106-1108, 1972.

[5] V. N. Smirnov, Dynamic Processes in Sea Ice, Gidrometeoizdat, St. Petersburg, Russia, 1996.

[6] V. N. Smirnov, A. N. Shushlebin, and V. G. Korostelev, "Results of experimental measurements of the parameters of surface and internal waves in the Arctic ocean and the sea of Okhotsk," in Surface and Internal Waves in the Arctic Seas, I. V. Lavrenov and E. G. Morozov, Eds., Gidrometeoizdat, St. Petersburg, Russia, 2002.

[7] S. V. Muzylev, "Internal waves under an ice cover," Doklady Earth Sciences, vol. 418, no. 1, pp. 145-148, 2008.

[8] S. V. Muzylev and L. N. Oleinikova, "On the theory of internal waves under ice cover," Oceanology, vol. 47, no. 2, pp. 172-177, 2007.

[9] L. D. Landau and E. M. Lifshitz, Theory of Elasticity, Pergamon, Oxford, UK, 1967.

[10] A. K. Liu and E. Mollo-Christensen, "Wave propagation in a solid ice pack," Journal of Physical Oceanography, vol. 18, no. 11, pp. 1702-1712, 1988.

[11] S. V. Muzylev, "Edge waves under ice cover at a straight coast with a sloping beach," Oceanology, vol. 46, no. 4, pp. 465-471, 2006.

[12] V. V. Bogorodsky and V. P. Gavrilo, Ice: Physical Properties, Modern Methods in Glaciology, Gidrometeoizdat, Leningrad, Russia, 1983.

[13] M. Coon, D. C. Echert, and G. S. Knoke, "Ice in surface waters," in Proceedings of the 14th International Symposium on Ice, H. T. Shen, Ed., pp. 1049-1055, Balkema, 1999.

[14] A. Marchenko, "Parametric excitation of flexural-gravity edge waves in the fluid beneath an elastic ice sheet with a crack," European Journal of Mechanics B, vol. 18, no. 3, pp. 511-525, 1999.

[15] A. V. Marchenko, "Flexural gravity waves," Trudy Instituta Obshchei Fiziki, vol. 56, pp. 65-111, 1999.

[16] A. Marchenko, I. Langen, and A. Shestov, "Hydrological characteristics of the strait separating Braganzavagen from Sveabukta in Van Mijen Fjord," in Coastal Technology-Coast 2008, NTNU, Trondheim, Norway, 2008.

[17] A. Marchenko, A. Shestov, A. Karulin et al., "Field studies of sea water and ice properties in Svalbard fjords," in Proceedings of the International Conference on Port and Ocean Engineering under Arctic Conditions (POAC '11), pp. 148-160, 2011.

[18] "The Winter-Expedition of RV "Polarstern" to the Antarctic (ANT V/1-3)," Berichte zur Polarforschung, Nr. 39, AlfredWegener-Institut für Polar- und Meeresforschung, Bremerhaven, Germany, 1987.
[19] J. R. Marko, "Observations and analyses of an intense wavesin-ice event in the Sea of Okhotsk," Journal of Geophysical Research, vol. 108, no. 9, pp. 3296-3309, 2003.

[20] I. V. Polyakov, L. A. Timokhov, V. A. Alexeev et al., "Arctic ocean warming contributes to reduced polar ice cap," Journal of Physical Oceanography, vol. 40, no. 12, pp. 2743-2756, 2010. 

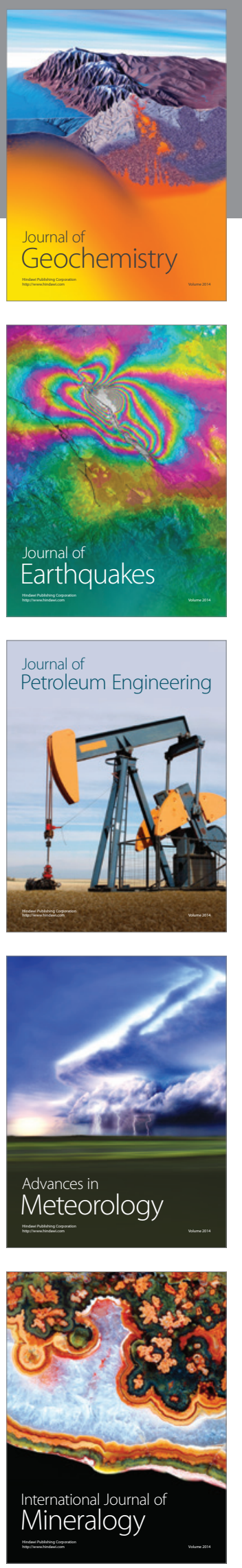
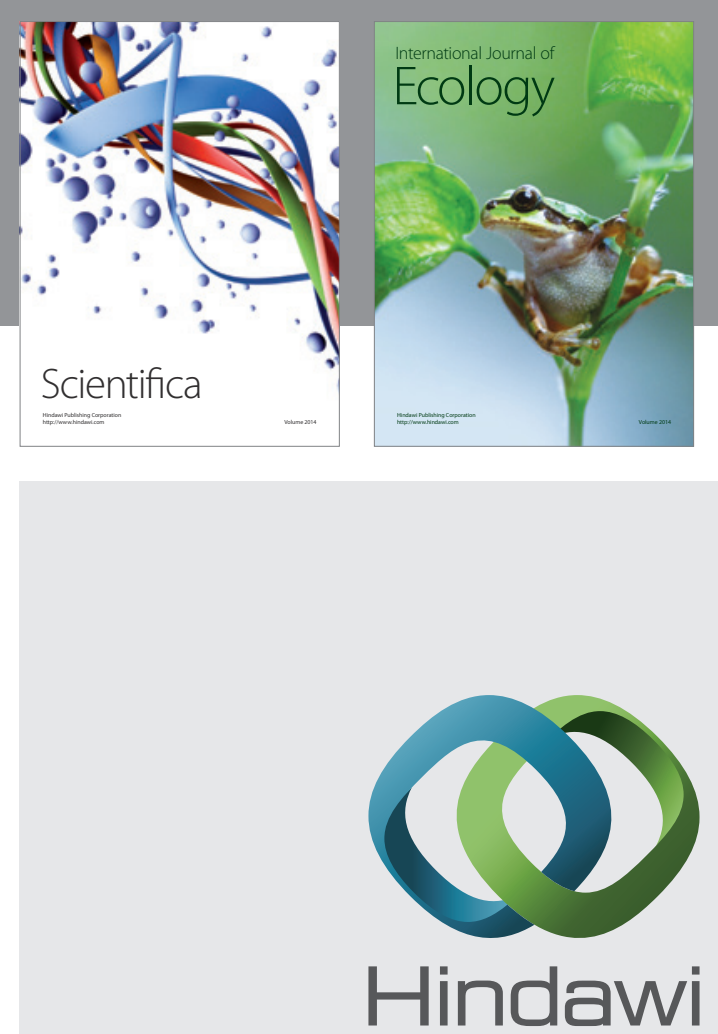

Submit your manuscripts at http://www.hindawi.com
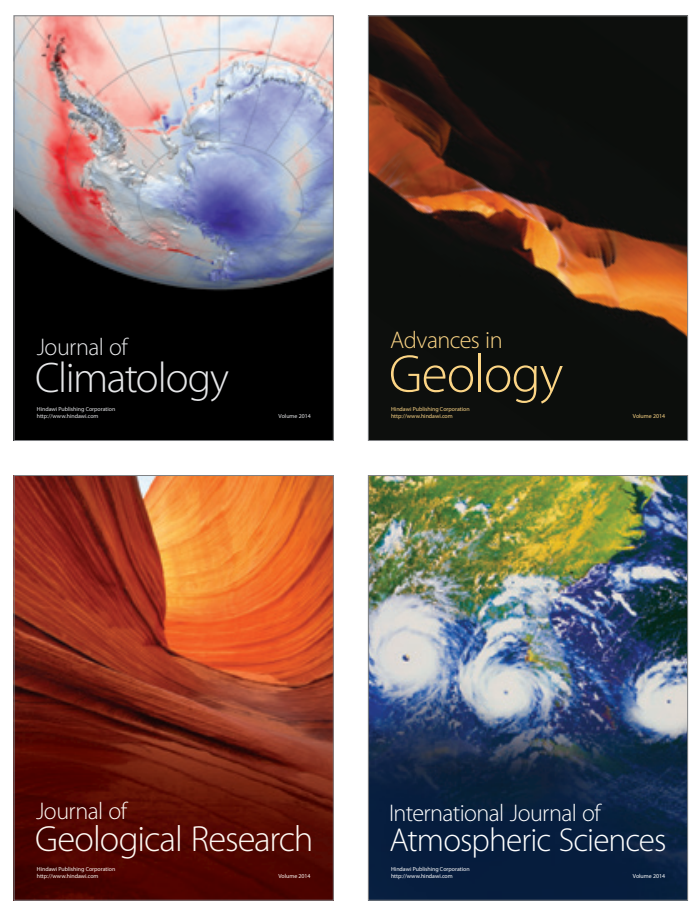
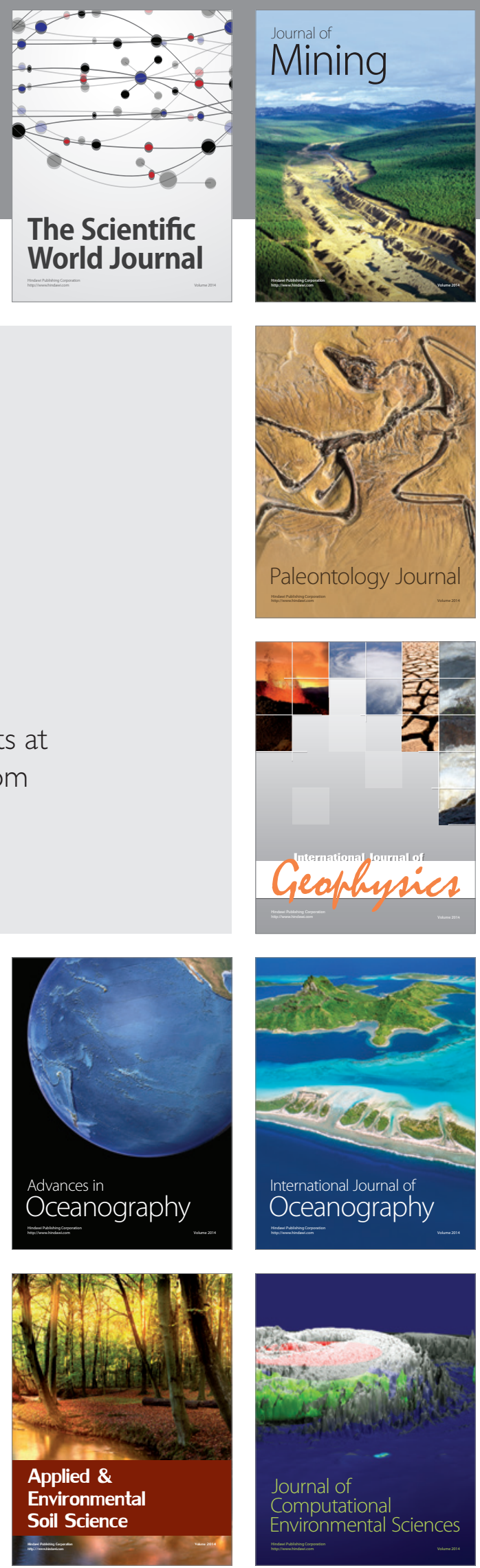